\title{
Effect of progressive muscle relaxation on post-operative analgesia
}

\author{
Devi $\mathbf{R}^{1}$, Saharia $\mathbf{H K}^{2}$ \\ ${ }^{1}$ Ms. Rajita Devi, Lecturer, Medical Surgical Nursing, College of Nursing, Hayat Institute of Nursing Education, Hayat \\ Hospital, Guwahati, Assam, ${ }^{2}$ Dr. Hiranya Kumar Saharia, Anaesthesiology, Assistant Professor, Anaesthesiology and \\ Critical Care, Gauhati Medical College, Guwahati, Assam, India.
}

Address for Correspondence: Dr. Hiranya Kumar Saharia, Email: sahariahiranya @gmail.com

\begin{abstract}
Background: Postoperative pain begins with surgical trauma, the intensity reduces gradually and ends with tissue recovery. Effective pain management is essential to minimize unnecessary distress and potential complications. Aim: The study aimed to assess the effect of progressive muscle relaxation technique on post-operative analgesia in patients undergoing abdominal surgery. Materials and Methods: Evaluative research approach, quasi experimental time series design and simple random sampling technique were used to select 20 samples in experimental and control group respectively. Results: Progressive muscle relaxation was the only influencing factor on reducing pain on $1^{\text {st }}$ and $2^{\text {nd }}$ postoperative day and no significant association was found between the research variables and level of pain. Mean arterial pressure was positively correlated with level of pain $(<0.05)$. Conclusion: Progressive muscle relaxation technique was effective in reducing post-operative pain and the results of this study can be incorporated in surgical units for proper management of post-operative analgesia.
\end{abstract}

Keywords: abdominal surgery, post-operative pain, numerical pain rating scale, progressive muscle relaxation.

\section{Introduction}

Pain is a complex, multidimensional experience. The International Association for the Study of Pain (IASP) defines pain as "an unpleasant sensory and emotional experience associated with actual or potential tissue damage, or described in terms of such damage" [1]. Many factors are known to affect the experience of pain, including gender, age, culture, previous experiences, the meaning the pain has to the individual experiencing it, tempered with a range of psychological factors, the most predominant of which is individual coping skills [2]. The number of abdominal surgeries is expected to increase from around 7,436,000 surgeries in 2010 to $8,109,000$ surgeries in 2020 [3]. Improper pain control not only increases the burden of many organs, but also limits the patient's activity, increases postoperative morbidity, affects physical recovery and the patient's emotional state after surgery, and is more likely to extend the length of stay and medical costs [4]. No study has been conducted so far on effectiveness of

Manuscript received: $18^{\text {th }}$ January 2017

Reviewed: $24^{\text {th }}$ January 2017

Author Corrected: $1^{\text {st }}$ February 2017

Accepted for Publication: $8^{\text {th }}$ February 2017 progressive muscle relaxation in entire North- East region, so the investigators has undertaken this study which will give evidence based practice to health personnel working in surgical units to improve the quality of life of patients.

\section{Aims and objectives of the study}

1. To assess the level of pain in patients undergoing abdominal surgery.

2. To determine the effectiveness of progressive muscle relaxation technique on pain management in patients undergoing abdominal surgery.

3. To determine the association between the level of pain and selected variables like age, sex, marital status, type of anaesthesia and type of surgery in patients undergoing abdominal surgery.

4. To correlate the physiological parameters like pulse, respiration and blood pressure with the level of pain in patients undergoing abdominal surgery in experimental group. 


\section{Materials and Methods}

This was a quasi-experimental study with time series design on randomised post-operative patients who underwent elective open abdominal surgery and were admitted in general surgery wards in some selected hospitals of Guwahati, Assam.

All adult patients (aged 20-60 years) subjected to elective abdominal surgeries (appendicectomy, cholecystectomy, hernioplasty, gastrectomy gastrojejunostomy) were included in the study.

The exclusion criteria were: patients who developed post-operative complications such as peritonitis, postoperative haemorrhage, mild atelectasis, fever etc. and patients who were posted for emergency abdominal surgery.

The tool consisted of 3 parts, section I, II and III.

Section I: self-structured interview schedule developed by the investigator to collect the selected variables like age, sex, education, occupation, religion marital status, type of anaesthesia, type of surgery, and family support.

Section II: consist of numerical pain rating scale, which is a self-administered standardized tool developed by Margo McCaffery [5] which has $10 \mathrm{~cm}$ baseline as per the recommendations. The subjects were asked to rate the pain on the numerical pain rating scale.

The pain score has been classified into the following'no pain' (0), 'mild pain' (1-3) 'moderate pain' (4-6), 'severe pain' (7-10).

Section III: pre and post-test assessment of physiological parameters like pulse, respiration and blood pressure.

\section{Results}

\section{Distribution of samples according to selected variables}

Age- It was observed that, in experimental group majority of patients (40\%) were in the age group of 31-40 years, whereas majority of patients were in the age group of 20-30 years (35\%) and 31-40 years (35\%) in the control group.

Sex-Equal numbers (50\%) of male and female patients were found in both the experimental and control group.

Marital status- Majority of patients were married, $70 \%$ in the experimental group $75 \%$ in the control group.

Type of anaesthesia- All the patients had undergone surgery under general anaesthesia in both the groups.

Type of surgery-Majority of patients had undergone cholecystectomy, $65 \%$ in the experimental group and 55\% in the control group.
Reliability of the structured interview schedule was tested by using Spearman Brown coefficient and ' $r$ ' obtained was 0.801 which indicated that the tool was reliable.

After obtaining permission from the Institutional ethical Committee and written consent was from all the participants of the study after explaining the purpose and other details of the study, the present study was conducted on some selected hospitals of Guwahati, Assam from 1st January 2014 to 31st January 2015. The samples of the study were selected by convenient sampling method, lottery was done to randomly select the experimental and control group.

One day prior to the surgery, progressive muscle relaxation technique was taught and verbal instruction was given for the experimental samples.

Pre-test level of pain was assessed and progressive muscle relaxation was given as intervention for three consecutive post-operative days starting from the first post-operative day and post test was conducted every day in both.

Progressive muscle relaxation was given for 15 minutes and post test was conducted after 1 hour to assess the effectiveness of progressive muscle relaxation on postoperative pain.

Statistical analysis- Data analysis was done by using the SPSS Version 15. Frequency, percentage, mean and standard deviation, paired 't' test, chi-square test and pearson's correlation test was done to assess the effect of progressive muscle relaxation. The level of significance was set at 0.05 levels to interpret the findings. 


\section{Assessment of pre-test level of pain in patients undergoing abdominal surgery}

In the pre-test assessment of level of pain in day 1, majority of patients in experimental group had moderate pain (90\%) as compared to $85 \%$ in the control group. In day 2, majority of patients in both experimental group and control group had moderate pain that is $75 \%$ and $65 \%$ respectively. In day 3, majority of patients had mild pain, $95 \%$ in the experimental group and $85 \%$ in the control group. (Table 2)

Table 1: Assessment of pre-test level of pain.

$\mathrm{n}=40$ (Experimental group $=20$, Control group $=20)$.

\begin{tabular}{|c|c|c|c|c|c|c|}
\hline Day & \multicolumn{3}{|c|}{ Experimental group } & \multicolumn{3}{c|}{ Control group } \\
\hline & Mild & Moderate & Severe & Mild & Moderate & Severe \\
\hline Day 1 & -- & $18(90 \%)$ & $2(10 \%)$ & $2(10 \%)$ & $17(85 \%)$ & $1(5 \%)$ \\
\hline Day 2 & $5(25 \%)$ & $15(75 \%)$ & -- & $7(35 \%)$ & $13(65 \%)$ & -- \\
\hline Day 3 & $19(95 \%)$ & $1(5 \%)$ & -- & $17(85 \%)$ & $3(15 \%)$ & -- \\
\hline
\end{tabular}

\section{Assessment of post-test level of pain in patients undergoing abdominal surgery}

On post-test assessment of level of pain on day 1, majority of patients had moderate pain in the experimental group $(80 \%)$ as well as in the control group (90\%).

On day 2, majority of patients had mild pain in the experimental group (75\%) whereas 50\% patients had mild pain and $50 \%$ had moderate pain in control group. On day 3 , all the patients had mild pain $(100 \%)$ in experimental group whereas majority of patients had mild pain $(85 \%)$ in control group.

Table 2: Assessment of post-test level of pain.

$\mathrm{n}=40($ Experimental group $=20$, Control group $=20)$

\begin{tabular}{|c|c|c|c|c|c|c|}
\hline Day & \multicolumn{3}{|c|}{ Experimental } & \multicolumn{3}{c|}{ Control } \\
\hline & mild & moderate & severe & mild & moderate & severe \\
\hline Day 1 & $4(20 \%)$ & $16(80 \%)$ & -- & $2(10 \%)$ & $18(90 \%)$ & -- \\
\hline Day 2 & $15(75 \%)$ & $5(25 \%)$ & -- & $10(50 \%)$ & $10(50 \%)$ & -- \\
\hline Day 3 & $20(100 \%)$ & -- & -- & $17(85 \%)$ & $3(15 \%)$ & -- \\
\hline
\end{tabular}

Determination of the effectiveness of progressive muscle relaxation technique on pain management in patients undergoing abdominal surgery

Statistically it was revealed that there was significant reduction in the level of post-operative pain after the administration of progressive muscle relaxation on day $1(\mathrm{p}=0.02)$ and day $2(\mathrm{p}=0.002)$ in the experimental group and thus can be interpreted that progressive muscle relaxation was an effective intervention for reducing post-operative pain after abdominal surgery.

On the day 3 , there was significant reduction in level of pain in both experimental $(\mathrm{p}=0.001)$ and control group ( $\mathrm{p}=0.001)$ irrespective of application of progressive muscle relaxation technique to experimental group.

It may be due to individual's physiological adaptation, pain has reduced in both the groups and also the study indicated that intensity of pain is more on 1st and 2nd post-operative day and it was reduced to mild level on 3rd postoperative day, so effectiveness of progressive muscle relaxation technique could not be found out on 3rd post-operative day. 
Table-3: Effectiveness of progressive muscle relaxation technique.

\begin{tabular}{|c|c|c|c|c|c|c|}
\hline \multicolumn{2}{|c|}{ Day 1} & Mean & SD & $\mathbf{t}$ & df & P value \\
\hline \multirow[t]{2}{*}{ Experimental } & Pre-test & 5.50 & 0.95 & \multirow[t]{2}{*}{3.68} & \multirow[t]{2}{*}{19} & \multirow[t]{2}{*}{$0.02^{*}$} \\
\hline & Post-test & 5.00 & 1.21 & & & \\
\hline \multirow[t]{2}{*}{ Control } & Pre-test & 5.00 & 1.08 & \multirow[t]{2}{*}{1.00} & \multirow[t]{2}{*}{19} & \multirow[t]{2}{*}{$0.33 \mathrm{NS}$} \\
\hline & Post-test & 4.95 & 1.05 & & & \\
\hline \multicolumn{2}{|c|}{ Day 2} & Mean & SD & $\mathbf{t}$ & df & $P$ value \\
\hline \multirow[t]{2}{*}{ Experimental } & Pre-test & 4.10 & 0.97 & \multirow[t]{2}{*}{10.38} & \multirow[t]{2}{*}{19} & \multirow[t]{2}{*}{$0.002^{* * *}$} \\
\hline & Post-test & 3.25 & 0.97 & & & \\
\hline \multirow[t]{2}{*}{ Control } & Pre-test & 4.15 & 1.09 & \multirow[t]{2}{*}{2.52} & \multirow[t]{2}{*}{19} & \multirow[t]{2}{*}{$0.33 \mathrm{NS}$} \\
\hline & Post-test & 5.90 & 1.29 & & & \\
\hline Day 3 & & Mean & SD & $t$ & df & $P$ value \\
\hline \multirow[t]{2}{*}{ Experimental } & Pre-test & 2.45 & 0.94 & \multirow[t]{2}{*}{5.63} & \multirow[t]{2}{*}{19} & \multirow[t]{2}{*}{$0.001^{* *}$} \\
\hline & Post-test & 1.45 & 0.69 & & & \\
\hline \multirow[t]{2}{*}{ Control } & Pre-test & 2.63 & 0.99 & \multirow[t]{2}{*}{1.00} & \multirow[t]{2}{*}{19} & \multirow[t]{2}{*}{$0.001^{* *}$} \\
\hline & & 2.60 & 0.88 & & & \\
\hline
\end{tabular}

** Significant at $\mathrm{P}(<0.01) *$ significant at $\mathrm{P}(<0.05)$, NS- Non significance

\section{Assessment of association between the level of pain and selected variables}

The present study revealed that there is no statistically significant association between level of post-operative pain with age of patients, sex, marital status, type of anaesthesia and type of surgery at $p<0.05$ level of significance.

\section{Assessment of correlation between physiological parameters like pulse, respiration and blood pressure and level of post-operative pain}

There was no significant correlation of level of pain with pulse $(\mathrm{r}=0.257)$ and respiration $(\mathrm{r}=0.652)$ but mean arterial pressure was positively correlated with level of pain $(r=0.045)$. It implies that as the level of pain increases, the mean arterial pressure also increases.

\begin{tabular}{|c|c|c|c|}
\hline Physiological parameters & Mean & SD & $\begin{array}{c}\text { Correlation related to } \\
\text { pain r value }\end{array}$ \\
\hline Pulse & 82.80 & 9.96 & $0.257 \mathrm{NS}$ \\
\hline Respiration & 24.50 & 5.15 & $0.652 \mathrm{NS}$ \\
\hline $\begin{array}{c}\text { Blood pressure } \\
\text { (Mean arterial pressure) }\end{array}$ & 88.00 & 9.82 & $0.045^{*}$ \\
\hline
\end{tabular}

* Significant at $\mathrm{P}<0.05$, NS- Non significance

\section{Discussion}

In the pre-test assessment of level of pain in day 1 , majority of patients in experimental group had moderate pain $(90 \%)$ as compared to $85 \%$ in the control group. In day 2, majority of patients in both experimental group and control group had moderate pain that is $75 \%$ and $65 \%$ respectively. In day 3 , majority of patients had mild pain, $95 \%$ in the experimental group and $85 \%$ in the control group.
On post-test assessment of level of pain on day 1, majority of patients had moderate pain in the experimental group (80\%) as well as in the control group (90\%).

On day 2, majority of patients had mild pain in the experimental group (75\%) whereas $50 \%$ patients had mild pain and $50 \%$ had moderate pain in control group. 
On day 3, all the patients had mild pain (100\%) in experimental group whereas majority of patients had mild pain $(85 \%)$ in control group.

The findings of the study were supported by a similar study by Chanif $\mathrm{C}$ et al. [6], where it was reported that on average, postoperative patients had experienced moderate to severe pain, both in their report of pain intensity and pain distress as evidenced by the range of scores from 4 to 9 out of 10 and median score of 5 and $6(\mathrm{IQR}=2)$, respectively. Another study conducted by Jeffrey L. A and et al. [7] in the United States, to describe severity of pain experienced by patient postoperatively and it was reported that $86 \%$ had moderate, severe, or extreme pain, with more patients experiencing pain after discharge than before discharge.

Statistically it was revealed that there was significant reduction in the level of post-operative pain after the administration of progressive muscle relaxation on day $1(p=0.02)$ and day $2(p=0.002)$ in the experimental group and thus can be interpreted that progressive muscle relaxation was an effective intervention for reducing post-operative pain after abdominal surgery.

On the day 3, there was significant reduction in level of pain in both experimental $(\mathrm{p}=0.001)$ and control group $(\mathrm{p}=0.001)$ irrespective of application of progressive muscle relaxation technique to experimental group. It may be due to individual's physiological adaptation, pain has reduced in both the groups and also the study indicated that intensity of pain is more on 1st and 2nd post-operative day.

A similar study was conducted by Topcu SY and et al. [8] on effect of relaxation exercises on controlling postoperative pain and it was reported that $71.7 \%$ of the patients felt less pain after the relaxation exercises $(\mathrm{z}=-5.497 ; \mathrm{p}<.001)$.

Good $\mathrm{M}$ et al. [9] supported the study by determining the effect of jaw relaxation, music and the combination of relaxation and music on postoperative pain after major abdominal surgery during ambulation and rest on postoperative days 1 and 2 . Result shows that all the three treatment groups had significantly less pain than the controls, $(\mathrm{P}=0.028-0.000)$ which was confirmed by the univariate analysis of covariance $(\mathrm{P}=0.018-0.000)$. Post hoc multivariate analysis revealed that the combination group had significantly less sensation and distress of pain than the control group on all post-tests
$(\mathrm{P}=0.035-0.000)$, and the relaxation and music groups had significantly less on all tests $(\mathrm{P}=0.022-0.000)$ except after ambulation.

The study findings could not be generalized because it included patients who had undergone different surgical procedure which lacks homogeneity of study sample, the sample size was only 40 selected post-operative patients (20 in experimental group, 20 in control group) and association of level of pain with type of anaesthesia could not be computed because all patients underwent surgery under general anaesthesia.

The present study recommends that similar study may be replicated on a larger sample which may help to draw conclusions that are more definite and generalizable to a larger population and can be carried out taking no age limit and considering a specific type of abdominal surgery. Also similar study can be carried out in post-operative patients undergoing surgery other than abdominal surgery and controlling all the extraneous variables.

\section{Conclusion}

The study findings suggest that level of post-operative pain is independent of age, sex, education, occupation, religion, marital status, type of anaesthesia, type of surgery, and family support. So, all patients need to be assessed for fatigue severity and managed accordingly.

Moreover non pharmacological methods for management of problems are preferred over pharmacological methods. Of late the use of progressive muscle relaxation as an adjunct therapy for patients undergoing abdominal surgery has gained favour in minimizing the level of pain of post-operative patient as a promising intervention. Progressive muscle relaxation being one of the non-invasive and non-pharmacological techniques can be of great help and it should be incorporated in clinical practice to help post-operative patients overcome this distressing feeling and improve their quality of life.

\section{Funding: Nil, Conflict of interest: None. Permission of IRB: Yes}

\section{References}

1. Lewis, Heitkemper, Dirksen, O'Brien, Bucher. Medical-Surgical Nursing. Elsevier, a division of Reed Elsevier India Pvt. Ltd. 2011, pages: 109. 
2. Mackintosh C. Assessment and management of patients with post-operative pain. Nursing Standard 2007;22:5, 49-55. Available from http://www.uptodate. com/contents/management-of- postoperative-pain.

3.http://spradlinbodyworks.wordpress.com/2013/10/14/ abdominal-surgery-statistics/

4. Arslan \& Çelebioğl. Level of post-operative pain after abdominal surgery. J Res Med Sci. 2013; 18: 172177. Available from: www.medscape.com/viewarticle / 759618_2.

5. McCaffery M, Pasero C. Teaching patients to use a numerical pain-rating scale. Am J Nurs. 1999 Dec; 99 (12):22.

6. Chanif C, Wongchan P, Wimonrat C. Acute Postoperative Pain of Indonesian Patients after Abdominal Surgery. medianurs. 2012;2: 409- 420. Available. fromhttp://ejournal.undip.ac.id/index.php/medianers/arti cle/view/3986

7. Jeffrey L. A, Connie C, Mehta S.S, and Tong J. Gan. Postoperative Pain Experience: Results from a National Survey Suggest Postoperative Pain Continues to $\mathrm{Be}$ Undermanaged. Anesth Analg 2003;97:534-40. Available from http://clinicaldepartments.musc.edu/ medicine/education/residency/Acute\%20pain\%20Apfel baum.pdf

8. Topcu SY, Findik UY. Effect of relaxation exercises on controlling postoperative pain. Pain Manag Nurs. 2012 Mar;13(1):11-7. doi: 10.1016/j.pmn.2010.07.006. Epub 2010 Sep 21.

9. Good M, Stanton-Hicks M, Grass JA, Cranston Anderson G, Choi C, Schoolmeesters LJ, Salman A. Relief of postoperative pain with jaw relaxation, music and their combination.)Pain. 1999 May;81(1-2):163-72.

\section{How to cite this article?}

Devi R, Saharia HK. Effect of progressive muscle relaxation on post-operative analgesia. Int J Med Res Rev 2017;5(02):113-118. doi:10.17511/ijmrr. 2017.i02.03. 